\title{
Oxytocin Reduces Background Anxiety in a Fear-Potentiated Startle Paradigm: Peripheral vs Central Administration
}

\author{
Luke W Ayers', Galen Missig', Jay Schulkin ${ }^{3,4,5}$ and Jeffrey B Rosen*,' \\ 'Department of Psychology, Behavioral Neuroscience Program, University of Delaware, Newark, DE, USA; ${ }^{2}$ Neuroscience Graduate Program, \\ University of Vermont, Burlington, VT, USA; ${ }^{3}$ Department of Neuroscience, Georgetown University, Washington, DC, USA; ${ }^{4}$ Behavioral \\ Endocrinology Section, National Institute of Mental Health, Washington, DC, USA; ${ }^{5}$ Research Department, American College of Obstetricians and \\ Gynecologists, Washington, DC, USA
}

\begin{abstract}
Oxytocin is known to have anti-anxiety and anti-stress effects. Using a fear-potentiated startle paradigm in rats, we previously demonstrated that subcutaneously administered oxytocin suppressed acoustic startle following fear conditioning compared with startle before fear conditioning (termed background anxiety), but did not have an effect on cue-specific fear-potentiated startle. The findings suggest oxytocin reduces background anxiety, an anxious state not directly related to cue-specific fear, but sustained beyond the immediate threat. The goal of the present study was to compare the effects of centrally and peripherally administered oxytocin on background anxiety and cue-specific fear. Male rats were given oxytocin either subcutaneously (SC) or intracerebroventricularly (ICV) into the lateral ventricles before fear-potentiated startle testing. Oxytocin doses of 0.01 and $0.1 \mu g / k g ~ S C$ reduced background anxiety. ICV administration of oxytocin at doses from 0.002 to $20 \mu \mathrm{g}$ oxytocin had no effect on background anxiety or cue-specific fearpotentiated startle. The $20 \mu \mathrm{g}$ ICV dose of oxytocin did reduce acoustic startle in non-fear conditioned rats. These studies indicate that oxytocin is potent and effective in reducing background anxiety when delivered peripherally, but not when delivered into the cerebroventricular system. Oxytocin given systemically may have anti-anxiety properties that are particularly germane to the hypervigilance and exaggerated startle typically seen in many anxiety and mental health disorder patients.

Neuropsychopharmacology (20I I) 36, 2488-2497; doi: I0.1038/npp.20I I.I38; published online 27 July 201 I
\end{abstract}

Keywords: oxytocin; anxiety; fear; startle; PTSD

\section{INTRODUCTION}

Oxytocin is non-apeptide commonly known for its role in childbirth, breast feeding, pair-bonding, social behaviors, feeding, drinking, and the stress response (Carter et al, 2008; Gimpl and Fahrenholz, 2001; Neumann, 2008). This peptide is produced both peripherally at the uterus, ovaries, corpus luteum, prostate gland, testis, kidneys, adrenal gland and heart, and in the central nervous system in neurons of the paraventricular and supraoptic nuclei of the hypothalamus (Gimpl and Fahrenholz, 2001). A large population of these hypothalamic cells projects to the posterior pituitary gland where the peptide is released into the blood. A smaller population of hypothalamic neurons also projects directly to the thalamus, septum, striatum, hippocampal formation, olfactory bulbs, amygdala, bed nucleus of the stria terminalis, and numerous brainstem nuclei (Buijs et al, 1985; Buijs, 1980; Sawchenko and Swanson, 1985;

*Correspondence: Professor JB Rosen, Department of Psychology, University of Delaware, Newark, DE 19716, USA,

Tel: + 302831 4209, Fax: + 302831 3645,

E-mail: jrosen@udel.edu

Received 22 January 2011; revised 23 June 2011; accepted 23 June 2011
Sofroniew, 1983). It is thought that these central projections are the means through which oxytocin acts as a modulator of neural activity and may ultimately affect various behavioral and psychological processes.

Numerous behavioral studies in rodents have demonstrated oxytocin's potential as an anxiolytic compound. Oxytocin administered SC to rats before an open-field test showed significant reductions in anxiety-like behavior (de Wied et al, 1987; Klenerova et al, 2009; Uvnäs-Moberg et al, 1994). Oxytocin given both ICV and systemically to mice is anxiolytic in a four-plate test and elevated zero maze test (Ring et al, 2006). Oxytocin chronically administered ICV reduced anxious behavior in outbred and high-anxiety bred female rats (Slattery and Neumann, 2010; Windle et al, 1997). Rats administered oxytocin SC before passive avoidance testing showed reduced latencies for stepping down off the safe platform, which may reflect reduced anxiety (de Oliveira et al, 2007; de Wied et al, 1987). Posttraining SC oxytocin administration in mice also impaired retention in an inhibitory avoidance task, suggesting oxytocin interferes with memory consolidation (Boccia et al, 1998). Thus, both ICV and systemic administration of oxytocin appear to ameliorate anxiety and aversive learning in a number of paradigms (Rotzinger et al, 2010; Viviani and Stoop, 2008). 
Recently our lab has used a rodent fear-potentiated startle paradigm to test the effects of systemic oxytocin on fear and anxiety behavior (Missig et al, 2010). Fear-potentiated startle paradigms are used to probe the internal emotional state of animals and humans (Davis and Whalen, 2001; Grillon and Baas, 2003), and have substantial humananimal translational validity and relevance for anxiety disorders (Davis et al, 2010; Grillon and Baas, 2003). In our study, in addition to analyzing fear-potentiated startle (ie the difference in startle between cue-specific fearpotentiated startle and startle in the absence of the fear cue), we analyzed the difference in startle before rats were fear conditioned and startle after fear conditioning, called background anxiety (Figure 1). This work revealed that systemically administered oxytocin reduced the state of background anxiety while leaving cue-specific conditioned fear intact. This effect is different from other anti-anxiety compounds, which markedly reduce startle during the fearconditioned stimulus (CS), yet leave startle in the absence of the CS unaffected (Davis et al, 1993). A series of follow-up experiments revealed that this reduction of background anxiety by oxytocin is likely not due contextual conditioning or a reduction in the ability to startle (Missig et al, 2010). This background anxiety may be similar to increased startle responses to unsignaled, unexpected startle stimuli observed in panic and post-traumatic stress disorder patients (Grillon, 2002).

Revealing the central mechanisms of oxytocin's effect on this background anxiety state would be beneficial for both understanding the nature of the background anxiety state itself and for the potential of oxytocin as a treatment for anxiety disorders. In our previous study, oxytocin was given SC, and it was assumed that in enters the brain to directly interact with central oxytocin receptors. However, there is doubt as to whether oxytocin readily crosses the bloodbrain barrier in amounts sufficient to exert effects directly in the central nervous system (Ermisch et al, 1993; Mens et al, 1983). Thus, the focus of the current investigation is to examine the effect of oxytocin administered ICV $30 \mathrm{~min}$

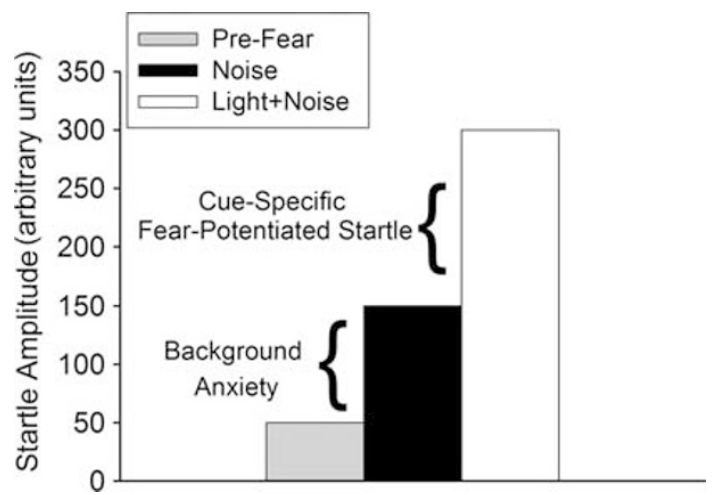

Figure I Startle responses from three different trial types were used to analyze the effects of oxytocin. Background anxiety is the increase in startle amplitude in the noise trials during the fear-potentiated startle test compared with the amplitude during the last acclimation session (pre-fear startle). pre-fear startle occurs before both fear conditioning and oxytocin administration. Cue-specific fear-potentiated startle is the increase in startle amplitude in the light + noise trials compared with the startle amplitude in the noise trials during the fear-potentiated startle test (adapted from Missig et al, 2010). before fear-potentiated startle testing, in order to determine if the effects seen mirror those of systemic administration.

\section{MATERIALS AND METHODS}

\section{Animals}

Male Sprague-Dawley rats weighing between 225 and $250 \mathrm{~g}$ were purchased from Charles River Breeders. Rats were pair-housed in shoebox cages in a climate-controlled facility with a 7:00 am-7:00 pm light/dark cycle, and had access to food and water ad libitum. After 1 week of arrival experimental procedures began; all performed between 8:00 am and 4:00 pm. All procedures were in accordance with the US National Institutes of Health Guide for the Care and Use of Experimental Animals and approved by the University of Delaware IACUC.

\section{Apparatus}

Eight identical SR Lab ventilated startle chambers with clear Plexiglas cylinders (San Diego Instruments, San Diego, CA) were used for all procedures involving the observation of startle in experiments 1,2 , and 4 . One wall of each chamber held an array of three LED lights aligned in parallel that produced 2600 lux and served as the CS. This light intensity does not significantly increase startle in unconditioned rats, but only potentiates startle once it becomes a fear CS (Supplementary Figure 1). A floor insert made of $104-\mathrm{mm}$ diameter stainless steel tubes placed $4 \mathrm{~mm}$ apart inside the Plexiglas cylinder was used to deliver foot shocks. Background white noise of $65 \mathrm{~dB}$ was continually played throughout all experimental sessions.

For experiment 3 , the observation of genital grooming behavior, rats were placed in one of four identical Plexiglas boxes $(16.5 \times 12.1 \times 21.6 \mathrm{~cm})$ with metal grid floors (nine stainless steel bars $4 \mathrm{~mm}$ in diameter and spaced $1.0 \mathrm{~cm}$ apart). This setup was positioned on a Plexiglas stand inside a fume hood with an overhead fluorescent light that illuminated the entire fume hood. A camera positioned to capture genital grooming behavior in the four chambers was attached to a Dell computer using FreezeFrame software set to the 4 chamber/1 mode (Actimetrics Software, Evanston IL). These chambers were also used to measure immobility in experiment 4 using the FreezeFrame and FreezeView software (Actimetrics Software, Evanston IL) to determine the percentage time spent immobile.

\section{Experiment 1: Effects of SC Administered Oxytocin on Background Anxiety and Fear-Potentiated Startle}

The startle paradigm used in this and the following studies follows a basic design consisting of 3 days of startle acclimation, 1 day of classical fear conditioning, followed by a fear-potentiated startle test session. The first 3 days of startle acclimation began with a 5-min acclimation period followed by 30 presentations of a $50 \mathrm{~ms}$ white noise burst startle stimulus at 95,105 , or $115 \mathrm{~dB}$ (10 of each) given in a predetermined pseudo-random order with a 15 -s inter-trial interval. These sessions served the triple role of acclimating the subjects to the experimental environment, matching subjects into experimental groups, and permitting mean 'Pre-Fear' startle scores to be constructed for each subject. These Pre-Fear scores were the mean of the startle 
amplitudes of all the trials over the 3 days. Rats with similar Pre-Fear startle amplitudes were assigned to different dose conditions so the various group Pre-Fear startle amplitudes were matched across conditions. Each dosing condition contained 12 subjects, with a total of 48 rats for the experiment. On the fourth day, all rats were classically fear conditioned. A 5-min acclimation period was followed by five pairings of light with a foot shock. Each pairing consisted of $3 \mathrm{~s}$ presentation of the light, which co-terminated with the $500 \mathrm{~ms}(0.6 \mathrm{~mA})$ foot shock; the inter-trial intervals ranged from 60 to $180 \mathrm{~s}$ in a pseudorandom order.

After $24 \mathrm{~h}$ fear-conditioning $0,0.01,0.1$, or $1.0 \mu \mathrm{g} / \mathrm{kg}$ of oxytocin dissolved in saline (Bachem Americas, Torrance, CA, catalog \# H-2510) was administered SC in the scruff of neck. Animals were weighed on the day of testing and injections were made while the experimenter gently held the animal. After $30 \mathrm{~min}$ of the administration rats were tested for retention of the conditioning in a fear-potentiated startle test. This test consisted of a $5 \mathrm{~min}$ acclimation period followed by 70 startle trials with $15 \mathrm{~s}$ intervals. The first 10 trials consisted of 95,105 , or $115 \mathrm{~dB}$ noise bursts presented in a predetermined pseudo-random order to re-acclimate subjects to the startle stimuli. The next 60 trials consisted of 95,105 , or $115 \mathrm{~dB}$ noise bursts presented either in the dark or co-terminating with the $3 \mathrm{~s}$ light CS presented in a pseudo-random order. For each noise burst intensity, 10 trials were presented in the absence of the light and 10 trials were presented in the presence of the light.

\section{Experiment 2: Effects of ICV Administered Oxytocin on Background Anxiety and Fear-Potentiated Startle}

Cannula implantation was performed 1 week following the subjects' arrival to the animal colony. Each rat was anesthetized via an intraperitoneal injection of a ketamine/xylazine cocktail (87 mg ketamine and $13 \mathrm{mg}$ xylazine/kg), and positioned in a stereotaxic surgical apparatus (Kopf Instruments, Tujunga, California). A guide cannula (22 ga) obtained from Plastics One (Roanoke, Virginia) measuring $10 \mathrm{~mm}$ total, with $5 \mathrm{~mm}$ extending from the base of the threads, was implanted in the left lateral ventricle of each subject (From Bregma: AP: -0.9 , LM: \pm 1.4 , DV: -2.4$)$. Following surgery each cannula was fitted with a 28 ga dummy injector placeholder (Plastics One) that was only removed for infusions, each 'dummy' extended $1 \mathrm{~mm}$ past the end of the guide into the ventricle.

After 1 week of the surgery, the behavioral training and testing of fear-potentiated startle procedure began, which was identical to experiment 1 with the exception of oxytocin administration on testing day. Infusions of oxytocin ICV were administered $30 \mathrm{~min}$ before testing on day 5 . Oxytocin was diluted in saline to obtain concentrations of $0.001,0.01$, $0.05,0.1$, or $1.0 \mu \mathrm{g} / \mu \mathrm{l}$. Rats were gently held while the dummy was removed and a 28 ga injector (Plastics One) was inserted into the guide extending $1 \mathrm{~mm}$ past its tip. The rats were then individually placed in empty shoebox cages to move freeing during the $5 \mathrm{~min}$ infusion procedure. After $1 \mathrm{~min}$ of the cannula insertion, the infusion began. All doses were infused at a rate of $1 \mu \mathrm{l} / \mathrm{min}$ for $2 \mathrm{~min}$, for a total volume of $2 \mu \mathrm{l}$ per animal (resulting in final doses of 0.002 , $0.02,0.1,0.2$, and $2.0 \mu \mathrm{g}$ ). The cannula remained in place for another 2 min. The rats were then removed from the cages and gently held while the injectors were removed and the dummies reinserted into the guide cannulas. Post-mortem examination of cannula placement was conducted to eliminate subjects with improperly placed guides missing the ventricle. Six saline, three $0.002 \mu \mathrm{g}$ OT, four $0.02 \mu \mathrm{g}$ OT, four $1.0 \mathrm{~g} \mu \mathrm{g}$ OT and two $2.0 \mu \mathrm{g}$ OT subjects were eliminated. Following this exclusion there was a total of 84 subjects (saline: $n=29 ; 0.002 \mu \mathrm{g}$ OT: $n=9 ; 0.02 \mu \mathrm{g}$ OT: $n=17 ; 0.1 \mu \mathrm{g}$ OT: $n=10 ; 0.2 \mu \mathrm{g}$ OT: $n=11 ; 2.0 \mu \mathrm{g}$ OT: $n=8$ ).

\section{Experiment 3: ICV Administered Oxytocin on Genital Grooming}

To assure that oxytocin in the range of ICV doses (0.002$2.0 \mu \mathrm{g}$ ) tested in experiment 3 were behaviorally active, a test of oxytocin-induced genital grooming was conducted following the protocol of Drago et al (1986). Cannulas were implanted in the same manner as described in experiment 2. After 1 week of the surgery saline, 0.1 or $1.0 \mu \mathrm{g}$ oxytocin was infused ICV at a rate of $0.5 \mu \mathrm{l} / \mathrm{min}$ for $2 \mathrm{~min}$. After $30 \mathrm{~min}$ rats were placed into a novel chamber and recorded for $30 \mathrm{~min}$. A person blind to the group membership of the rats counted the number of genital grooming bouts. A genital grooming bout was defined as the initiation of genitalspecific grooming behavior for a minimum of $5 \mathrm{~s}$.

Post-mortem examination of cannula placement eliminated three salines, one $0.1 \mu \mathrm{g}$ OT and two $1.0 \mu \mathrm{g}$ OT subjects because of misplaced guide cannula, so that the subject number totaled 20 (saline: $n=6 ; 0.1 \mu \mathrm{g}$ OT: $n=7$; $1.0 \mu \mathrm{g}$ OT: $n=7)$.

\section{Experiment 4: Effects of ICV Administered High Dose of Oxytocin on Background Anxiety and Fear-Potentiated Startle}

Because the oxytocin doses tested in experiments 2 and 3 did not affect startle but enhanced genital grooming (see Results), we decided to test a higher dose of oxytocin on background anxiety and fear-potentiated startle. The fearpotentiated startle paradigm was identical to that used in experiment 2 , except that a high dose of oxytocin $(20 \mu \mathrm{g})$ was given. Rats from experiment 3 and naive subjects were tested. Following post-mortem examination of cannula placements there was a total of 26 subjects: 11 subjects in the saline condition and 15 in the $20 \mu \mathrm{g}$ oxytocin condition.

A follow-up study was also conducted to test whether ICV administration of $20 \mu \mathrm{g}$ oxytocin suppressed the ability to startle without prior fear conditioning. Cannula implantation surgeries were performed, and 7 days following surgery all subjects underwent three startle acclimation sessions as described above. On the fourth day, the rats were not given fear conditioning nor tested for startle. On the fifth day, all subjects were given either oxytocin $(n=13)$ or saline $(n=10)$ infusions, then $30 \mathrm{~min}$ later were tested for acoustic startle in a session identical to the acclimation sessions. One oxytocin-treated rat was removed from the analysis because the injection missed the ventricles.

\section{Data Analysis}

For each component of the startle testing, the amplitudes of the 95,105 , and $115 \mathrm{~dB}$ noise bursts were averaged for each 
rat and used in the statistical analyses. The three startle components are (1) Pre-Fear: the mean startle of each group before fear conditioning, (2) noise: mean startle $24 \mathrm{~h}$ following conditioning in the absence of the light, and (3) light + noise: mean startle $24 \mathrm{~h}$ after fear conditioning in the presence of the CS + light (Figure 1). Both noise and light + noise startle responses were taken from a single test session.

The effect of oxytocin in the fear-potentiated startle test was analyzed by a mixed model ANOVA with a betweensubject measure of dose and within-subject measure of fearpotentiated startle (light + noise vs noise). Post-hoc analysis of a main effect of dose on startle was performed with a Dunnett's test to compare the various doses of oxytocin with the vehicle (saline). Fear-potentiated startle was analyzed in two different ways - absolute fear-potentiated startle and percentage fear-potentiated startle. An absolute fear-potentiated startle score was computed by subtracting the average Noise startle amplitude from the average light + noise startle amplitude for each rat. A percentage fearpotentiated startle score was computed for each subject by dividing their absolute fear-potentiated startle score by their noise startle amplitudes. The resulting quotient was then multiplied by 100 . Because oxytocin reduced startle during noise trials, the percentage fear-potentiated startle score was used to normalize fear-potentiated startle across groups (Walker and Davis, 2002a). These scores were used to analyze differences in fear-potentiated startle between the oxytocin doses and saline with a Dunnett's test.

Background anxiety was also analyzed by subtracting each subject's Pre-Fear score from its noise alone score. As each group was matched to have equal Pre-Fear scores, an absolute difference score was sufficient for analysis (Walker and Davis, 2002a). A mixed model ANOVA with a betweensubject measure of dose and within-subject measure of background anxiety (Pre-Fear vs noise) was then run on these scores. Post-hoc analysis of background anxiety was performed with a Dunnett's test to compare the various doses of oxytocin with the vehicle (saline).

Genital grooming bouts were defined as the initiation of a stereotypical grooming repertoire specific to the genital region; each bout was defined as lasting a minimum of $5 \mathrm{~s}$. General grooming behavior was not included. The number of grooming bouts was analyzed by using a standard twoway ANOVA.

In experiment 4 , startle was also tested in rats that did not receive fear conditioning. The acclimation session (preoxytocin) and oxytocin startle scores were statistically analyzed in a similar manner as the background anxiety measure of experiments 1 and 2 .

An $\alpha$ value of $p<0.05$ was considered a statistically significant difference for all of the analyses.

\section{RESULTS}

\section{Experiment 1: Systemically Administered Oxytocin Reduces Background Anxiety Following Fear Conditioning}

Graphs of the data from experiment 1 are shown in Figure 2a. Significant main effects were found for noise $v s$ light + noise trials $\left(\mathrm{F}_{1,44}=127.5, p<0.0001\right)$ and for oxytocin dose $\left(F_{3,44}=3.78, p<0.017\right)$. However, there was no

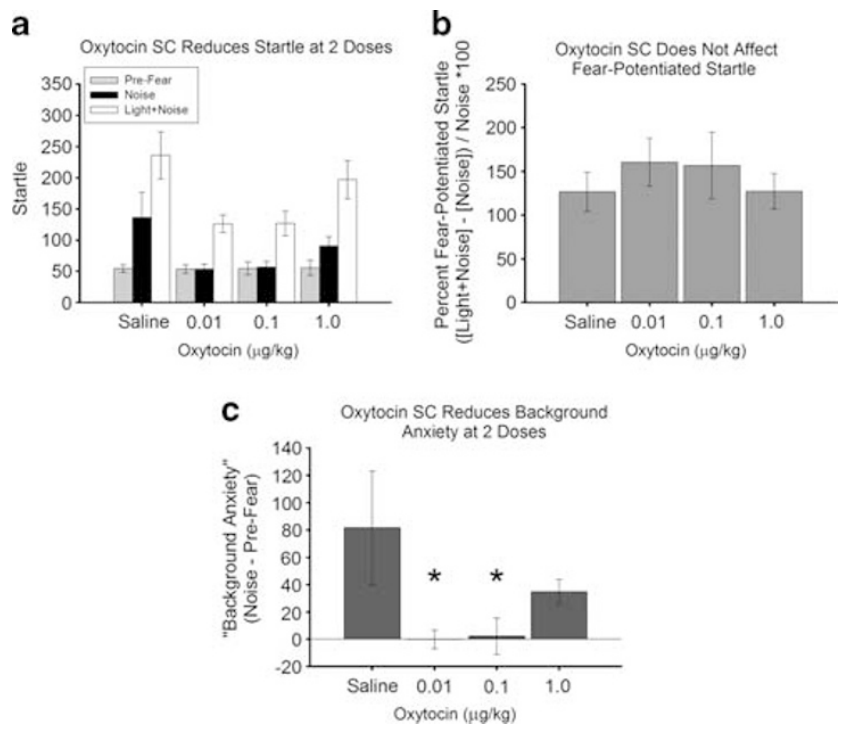

Figure 2 The effect of oxytocin administered SC 30 min before fearpotentiated startle testing. (a) Oxytocin at two doses $(0.01$ and $0.1 \mu \mathrm{g} / \mathrm{kg}$ ) significantly reduced startle during testing. (b) Percentage fear-potentiated startle. There was no effect of oxytocin. (c) Background anxiety. 0.00I and $0.01 \mu \mathrm{g} / \mathrm{kg}$ doses of oxytocin significantly reduced background anxiety compared with saline. *Indicates statistically significant from saline.

significant interaction between trial type and dose type $\left(\mathrm{F}_{3,44}=1.44, \mathrm{~ns}\right)$, indicating no specific effects of oxytocin on fear-potentiated startle. A Dunnett's post-hoc analysis revealed significant differences in startle between saline and $0.1 \mu \mathrm{g}$ oxytocin $(p<0.02)$, and between saline and $0.01 \mu \mathrm{g}$ oxytocin $(p<0.017)$ indicating that oxytocin administered systemically at two doses $(0.1 \& 0.01 \mu \mathrm{g} / \mathrm{kg}) 30 \mathrm{~min}$ before fear-potentiated startle testing significantly reduced overall startle on both noise and light + noise trials. Differences in percentage fear-potentiated startle scores between doses (Figure 2b) were analyzed using an univariate ANOVA, and revealed a lack of an effect of dose on fear-potentiated startle $\left(\mathrm{F}_{3,44}=0.43\right.$, ns $)$.

To evaluate oxytocin's effect on background anxiety, a repeated measures ANOVA was conducted comparing noise and pre-fear trials (Figure 2c). This revealed a significant main effect of dose $\left(\mathrm{F}_{3,44}=3.06, p<0.038\right)$ and a significant dose by trial interaction $\left(\mathrm{F}_{3,44}=2.89, p<0.05\right)$. A Dunnet's test background anxiety scores revealed significant differences between saline compared with oxytocin $0.01 \mu \mathrm{g} / \mathrm{kg}$ $(p<0.036)$ and saline compared with oxytocin $0.1 \mu \mathrm{g} / \mathrm{kg}$ $(p<0.042)$. Collectively, these results indicate that systemically administered oxytocin reduces background anxiety, an enhancement of startle to the noise alone that occurs following fear conditioning (Missig et al, 2010).

\section{Experiment 2: ICV Administered Oxytocin Does not Have any Effect on Startle}

To test whether ICV administration of oxytocin also decreases in background anxiety, we examined the effect of five doses of oxytocin $(0.002,0.02,0.1,0.2$, and $2 \mu \mathrm{g}$ ) compared with saline in the same fear-potentiated startle paradigm as experiment 1 . A repeated measures ANOVA comparing noise and light + noise trials revealed a 


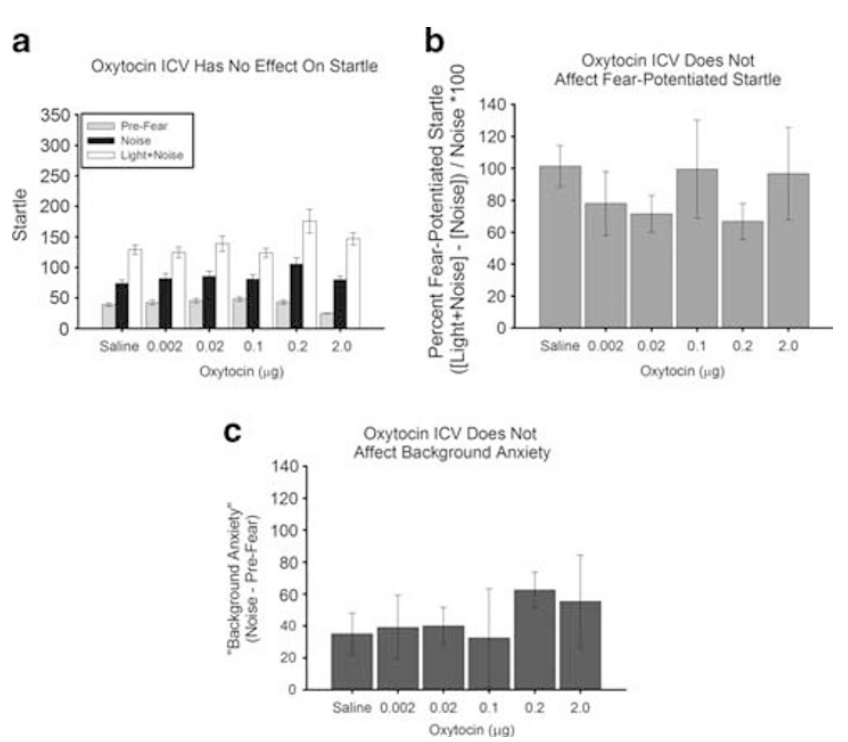

Figure 3 Oxytocin administered ICV at five doses (0.002-2.0 $\mu \mathrm{g} / \mathrm{rat}$ ) 30 min before fear-potentiated startle testing. (a) None of the doses had an effect on startle during testing. (b) Percentage fear-potentiated startle was unaffected by oxytocin. (c) There is no effect on background anxiety at any dose of oxytocin.

significant main effect of trial type $\left(\mathrm{F}_{1,78}=93.12\right.$, $p<0.0001$ ), yet no significant main effect of dose was present $\left(\mathrm{F}_{5,78}\right)=0.63$, ns) nor any interaction $\left(\mathrm{F}_{5,78}=0.57\right.$, $\mathrm{ns})$. Thus, it appears that while fear conditioning was successful and all groups displayed fear-potentiated startle, there was no effect of oxytocin given at any of the five doses on noise alone or light + noise startle (Figure 3a). Univariate ANOVA of percentage fear-potentiated startle scores confirmed the lack of an effect of oxytocin on fear-potentiated startle at these doses $\left(\mathrm{F}_{5,78}=0.78, \mathrm{~ns}\right)$ (Figure $3 \mathrm{~b}$ ). Lastly, the measure of background anxiety was examined via a repeated measures ANOVA comparing the noise with prefear scores (Figure 3c) revealing a significant main effect of trial type $\left(\mathrm{F}_{1,78}=61.09, p<0.0001\right)$ indicating increased background anxiety, yet there was no effect of dose $\left(\mathrm{F}_{5,78}=0.54, \mathrm{~ns}\right)$, nor an interaction $\left(\mathrm{F}_{5,78}=0.77, \mathrm{~ns}\right)$. Thus, it appears that ICV infusions of oxytocin at the doses tested had no effect on diminishing fear-potentiated startle or background anxiety when compared with control animals.

\section{Experiment 3: ICV Administered Oxytocin Potently Enhances Genital Grooming}

The lack of an effect ICV oxytocin on background anxiety at the same doses which were effective when administered SC, is curious because other behaviors have been found to be affected at these ICV doses. To make sure ICV oxytocin has behavioral effects in our hands we examined oxytocininduced genital grooming. We found oxytocin administered ICV at two doses $(0.1$ and $1.0 \mu \mathrm{g})$ significantly increased genital grooming behavior $\left(\mathrm{F}_{2,13}=32.95, p<0.0001\right)$. Furthermore, a Tukey's Honestly Significant Different post hoc analysis revealed saline, 0.1 , and $1.0 \mu \mathrm{g}$ oxytocin all differed from each other (saline $v s 0.1, p<0.001$; saline $v s$ $1.0, p<0.0001,0.1$ vs 1.0, $p<0.015$ ). These results (Figure 4) clearly demonstrate that oxytocin has a profound
Oxytocin ICV Enhances Genital Grooming at 2 Doses

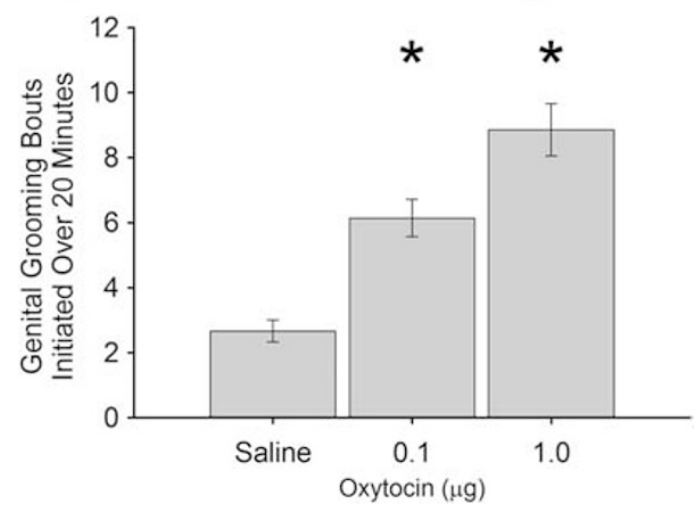

Figure 4 Oxytocin $(0.1$ and I.0 $\mu \mathrm{g})$ administered ICV 30 min before the observation of grooming behavior significantly enhanced the number of genital grooming bouts. *Indicates statistically significant from saline.

dose-dependent effect at enhancing genital grooming in a novel environment. The findings indicate that while ICV oxytocin induces genital grooming at certain doses, background anxiety is unaffected at these same doses.

\section{Experiment 4: ICV Administered Oxytocin Reduces Background Anxiety at a High Dose}

Following experiment 3 two additional groups of animals were tested with infusions of a higher ICV dose of oxytocin $(20 \mu \mathrm{g}) 30 \mathrm{~min}$ before fear-potentiated startle testing. In all, 12 subjects from experiment 3 were first retested with this higher dose (oxytocin $(n=8)$ and saline $(n=6)$, and upon finding a promising trend 14 new subjects were run (oxytocin $(n=7)$ and saline $(n=5)$. A statistical comparison between the two cohorts did not find any differences in any of the startle measures. Thus, to increase statistical power, the two cohorts were combined for analysis of fearpotentiated startle and background anxiety. A repeated measures ANOVA comparing the noise and the light + noise trials (Figure 5a) revealed a main effect of trial $\left(\mathrm{F}_{1,24}\right.$ $=46.57, p<0.0001)$ and a main effect of dose $\left(\mathrm{F}_{1,24}=9.79\right.$, $p<0.005)$. However, there was no interaction present between trial type and dose $\left(\mathrm{F}_{1,24}=0.89, \mathrm{~ns}\right)$. An univariate ANOVA of the percentage fear-potentiated startle scores also showed no oxytocin effect $\left(\mathrm{F}_{1,24}=0.72\right.$, ns) (Figure $5 \mathrm{~b}$ ). Lastly, for analysis of background anxiety a repeated measures ANOVA comparing the noise and pre-fear trials resulted in a main effect of dose $\left(\mathrm{F}_{1,24}=5.96, p<0.022\right)$, no effect of trial type $\left(\mathrm{F}_{1,24}=3.35, p<0.08\right)$, and also a significant interaction between trial type and dose $\left(\mathrm{F}_{1,24}=5.41, p<0.029\right)$ (Figure $\left.5 \mathrm{c}\right)$. Thus, with a high dose of oxytocin $(20 \mu \mathrm{g}), \mathrm{ICV}$ administration appears to reduce background anxiety.

An alternate explanation of the data is also possible. The effect of the high dose of oxytocin delivered ICV might have suppressed the ability to startle or respond to the acoustic stimulus instead of reducing background anxiety. To test whether oxytocin is merely reducing the startle response, rats were not fear conditioned, but tested for startle amplitude with or without oxytocin. Within-subject comparisons were made between mean startle responses during 

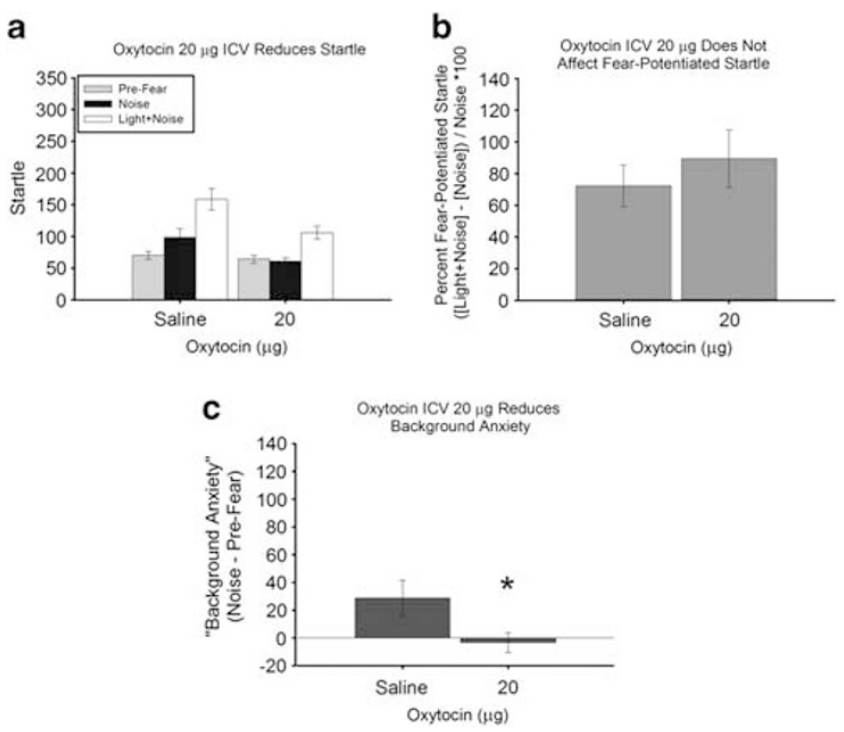

Figure 5 Oxytocin administered ICV at a high dose $(20 \mu \mathrm{g}) 30 \mathrm{~min}$ before fear-potentiated startle testing. (a) Oxytocin $(20 \mu \mathrm{g})$ significantly reduced startle. (b) Percentage fear-potentiated startle was unaffected by this high dose of oxytocin. (c) Background anxiety was significantly reduced by $20 \mu \mathrm{g}$ oxytocin. *Indicates statistically significant from saline.

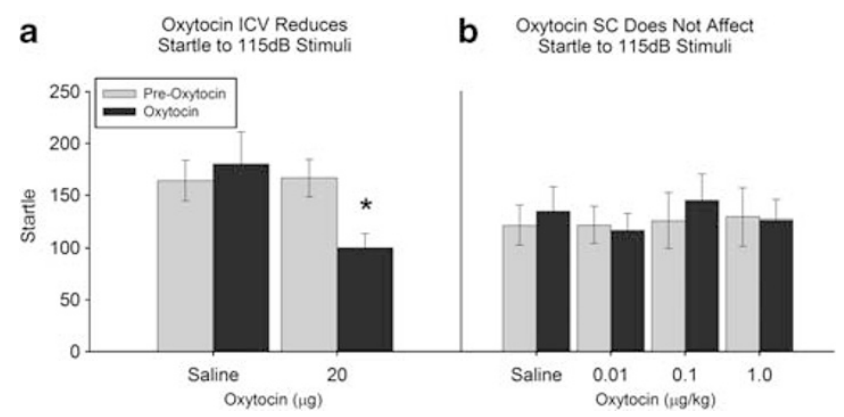

Figure 6 Effects of oxytocin non-conditioned acoustic startle. (a) Oxytocin $(20 \mu \mathrm{g})$ administered ICV significantly decreased startle elicited by the II $5 \mathrm{~dB}$ noise burst $(* 20.009)$. Startle elicited by 95 and $105 \mathrm{~dB}$ startle stimuli was not affected by oxytocin. (b) By comparison, oxytocin given SC at doses effective in reducing background anxiety did not affect acoustic startle in non-conditioned rats. Startle elicited by $115 \mathrm{~dB}$ noise burst is shown, but startle elicited by 95 and $105 \mathrm{~dB}$ noise bursts was also unaffected. Data from Figure 5 of Missig et al (2010).

acclimation and $30 \mathrm{~min}$ after saline or $20 \mu \mathrm{g}$ oxytocin administered ICV. There were no significant effects of the high ICV dose of oxytocin on startle amplitude (data not shown).

It is also possible that the lack of an effect of oxytocin on startle amplitude was because startle levels were very low in this experiment, and oxytocin may be more effective in reducing high levels of startle like those generated following fear conditioning. We therefore reanalyzed data of experiment 4 using startle amplitudes induced by the three startle stimulus intensities, 95, 105, and $115 \mathrm{~dB}$ noise bursts, individually. The 95 and $105 \mathrm{~dB}$ noise bursts had no effect, but at the $115 \mathrm{~dB}$ intensity, the $20 \mu \mathrm{g}$ ICV oxytocin dose significantly reduced acoustic startle (Figure 6). There was a significant interaction between acclimation startle (pre-oxytocin) and startle during $20 \mu \mathrm{g}$ oxytocin ICV $v s$ saline ICV $\left(\mathrm{F}_{1,20}=6.68, p<0.02\right)$. Further post-hoc analysis revealed that startle at $115 \mathrm{~dB}$ was significantly decreased by oxytocin $(p<0.009)$. The analysis suggests that the $20 \mu \mathrm{g}$ ICV dose of oxytocin reduced startle responsivity, but not background anxiety specifically, to a loud startle stimulus. Further observation of another group of rats given saline or $20 \mu \mathrm{g}$ oxytocin ICV in the chamber used to measure grooming, did not find discernable sedation or immobility. The percentage time spent immobile in a $30 \mathrm{~min}$ period after receiving $20 \mu \mathrm{g}$ oxytocin ICV was not different from saline infusion $\left(t_{22}=1.58, \mathrm{~ns}\right)$, indicating that the decrease in startle was not due to oxytocin producing sedation or immobility.

\section{DISCUSSION}

The goals of the present studies were to replicate our previous findings showing that systemically administered oxytocin reduces background anxiety without affecting cuespecific conditioned fear-potentiated startle (Missig et al, 2010), and examine whether centrally administered oxytocin has similar effects. Although our previous study was replicated, surprisingly, ICV infusion of oxytocin, even at a very high dose, did not have specific effects on background anxiety. These results have intriguing relevance for the controversy of whether it is necessary for peripherally administered oxytocin to enter the brain (Born et al, 2002; Pardridge, 2005) in order to have therapeutic effects in a number of mental health disorders including schizophrenia, anxiety disorders, depression, autism, and drug dependence (Bernier et al, 2005; Grillon et al, 2008, 2009; Hogle et al, 2010; Pole et al, 2003, 2009).

Background anxiety is thought to be an anxiety state that is not directly related to a cue-specific fear stimulus, but is activated by a conditioned fear stimulus (Missig et al, 2010).

Experiment 1 replicated and extended the findings of Missig et al (2010) by demonstrating that in addition to a reduction in background anxiety with SC administered oxytocin $96 \mathrm{~h}$ after fear conditioning, the same oxytocin doses $(0.01$ and $0.1 \mu \mathrm{g} / \mathrm{kg})$ reduced background anxiety when given and tested $24 \mathrm{~h}$ after fear conditioning. In both studies the reduction in startle was specific to background anxiety and did not affect cue-specific fear-potentiated startle. Furthermore, the Missig et al, study demonstrated that oxytocin could also be given before or shortly following fear conditioning indicating that oxytocin reduces background anxiety not only during testing or expression of fear, but also when fear is being learned or consolidated and then carried over to a later testing session. Oxytocin appears to uniquely and specifically reduce background anxiety, and this amelioration might have long-lasting effects.

ICV injections of oxytocin in the same dose range (0.002$2.0 \mu \mathrm{g})$ that was effective SC had no effect on background anxiety or on any measure of startle. Because this was not expected, we tested whether our ICV injection method was not successfully administering oxytocin into the ventricles. Because grooming is induced by oxytocin and many other neuropeptides (Colbern and Gispen, 1988), we therefore tested oxytocin elicitation of genital grooming with 0.1 and $1.0 \mu \mathrm{g} \mathrm{ICV} \mathrm{doses.} \mathrm{Genital} \mathrm{grooming} \mathrm{behavior} \mathrm{was} \mathrm{potently}$ enhanced and replicates previous studies with ICV and 
peripheral oxytocin administration (Amico et al, 2004; Drago et al, 1986; Van Erp et al, 1993a). This indicated that oxytocin's lack of effect in the dose range tested in the potentiated startle paradigm was not due to our ICV infusion procedures or the integrity of oxytocin administered ICV.

The high-ICV oxytocin dose of $20 \mu \mathrm{g}$ appeared to reduce background anxiety in a manner comparable to systemic administration, but in non-fear conditioned rats this dose reduced acoustic startle elicited with the $115 \mathrm{~dB}$ intensity stimulus. This indicates that the $20 \mu \mathrm{g}$ ICV oxytocin dose reduced startle without specifically effecting background anxiety, and differs from oxytocin administered systemically in non-conditioned rats which did not reduce acoustic startle elicited by a $115 \mathrm{~dB}$ startle stimulus (Missig et al, 2010).

The results beg the question of the locus of action of oxytocin on background anxiety. Comparing ICV and peripheral administration is typically done to differentiate central and peripheral hormone and drug effects ((Francis et al, 2006; Gibbs et al, 1981; Johnson and Epstein, 1975; Simpson, 1975). Conventional wisdom suggests that effective doses of a psychoactive compound should be less when administered directly into the ventricles than peripheral administration, because the compound would distribute throughout the cerebral spinal fluid and diffuse to adjacent and distal brain regions where active sites reside (Francis et al, 2006). However, the lack of an effect on background anxiety with ICV administration of oxytocin does not support this notion. Indeed, it is unclear whether peripherally administered oxytocin enters the brain in sufficient quantities to have direct central effects. Although there is carrier-mediated transport of oxytocin to excrete oxytocin from brain to blood (Durham et al, 1991), a transport system for oxytocin across the blood-brain barrier from the periphery into brain has not been identified (Brasnjevic et al, 2009). It has been estimated that approximately $0.002 \%$ of peripherally administered oxytocin penetrates into brain (Mens et al, 1983), but this is likely not sufficient to pass through the blood-brain barrier in physiologically significant amounts (Ermisch et al, 1985).

Our effect of peripherally, but not centrally, administered oxytocin to reduce background anxiety may have relevance for the site of action of oxytocin in humans. Oxytocin is typically administered intranasally, and is thought to enter the brain to effect anxiety and social behavior in normal and clinical subjects (Bartz et al, 2010; Domes et al, 2007; Kirsch et al, 2005; Kosfeld et al, 2005; Simeon et al, 2011). However, studies have shown that intravenous and intranasal administrations of oxytocin have similar effects on social behavior in autism spectrum disorder individuals (Bartz and Hollander, 2008; Hollander et al, 2003, 2007), suggesting that the effects are initiated in the periphery.

As fear and anxiety are central states, alterations of brain processes are essential for oxytocin to produce its antianxiety effects. Peripheral mechanisms for oxytocin to reduce background anxiety are not known, but could include regulation of autonomic and hypothalamic-pituitary-adrenal axis function (Grippo et al, 2009; Kiss and Mikkelsen, 2005). Peripheral oxytocin decreases heart rate and blood pressure (Gimpl and Fahrenholz, 2001; Petersson et al, 1996), alters corticosterone levels (Petersson et al,
1999), and may affect blood-brain barrier permeability by altering the transport of essential substances (Ermisch et al, 1993), which then might influence brain processes of emotion and anxiety.

Peripherally administered oxytocin might specifically affect oxytocin brain systems. Peripherally administered oxytocin has been shown to increase neural activity as measured by neuronal Fos expression in oxytocin-producing neurons of the supraoptic and paraventricular hypothalamic nuclei, and areas known to be important for anxiety, such as the central nucleus of the amygdala, locus coeruleus, and parabrachial nucleus (Carson et al, 2010) that contain oxytocin receptors (Tribollet et al, 1992). Oxytocin-synthesizing neurons in the paraventricular hypothalamic and supraoptic nuclei have extensive networks of dendrites and axons, which penetrate into the ventricles and subarachnoid space to release oxytocin (Veening et al, 2010). Oxytocin receptors in many brain areas are potentially activated by oxytocin released or injected into the CSF, including the paraventricular hypothalamic nucleus (Gimpl and Fahrenholz, 2001; Veening et al, 2010). Whereas these oxytocin receptive areas along the ventricles and subarachnoid space may mediate many behaviors, including grooming, following ICV administration of oxytocin (Stivers et al, 1988; Van Erp et al, 1993b; Veening et al, 2010), background anxiety does not appear to be one of these. Nevertheless, site-specific oxytocin injections into the paraventricular hypothalamic nucleus or central nucleus of the amygdala have been shown to decrease anxious behavior (Bale et al, 2001; Blume et al, 2008). Anxious behavior was also diminished by ICV chronic, but not single, infusions in outbred and highanxiety bred female rats (Slattery and Neumann, 2010; Windle et al, 1997). Further, anxiety-like behavior was diminished in mice by a single ICV oxytocin infusion, but this decrease in anxiety was immediately following anesthesia and acute neurosurgery (Ring et al, 2006). Whether oxytocin delivered ICV chronically or acutely at the time of surgery is transported to the periphery to be effective or has central effects is unknown.

In conclusion, the reduction in background anxiety by oxytocin appears to be through mechanisms that are either initiated in the periphery or in brain via transport through normal blood vasculature routes. Background anxiety is likely an important dimension of anxiety that is expressed in many mental health disorders. PTSD, panic disorder, and autism spectrum subjects, behaviorally inhibited adolescents, and people going through nicotine withdrawal display enhanced startle during unpredictable threat, but still have normal cued-fear-potentiated startle (Bernier et al, 2005; Brunetti et al, 2010; Dichter et al, 2010; Grillon and Morgan, 1999; Grillon et al, 1996, 1998, 2009; Hogle et al, 2010; Morgan et al, 1995; Pole et al, 2003, 2009; Reeb-Sutherland et al, 2009; Wilbarger et al, 2009). The disorders appear to share a clinical phenotype characterized by anxious apprehension, hypervigilance, and exaggerated responsivity during unpredictable, but not predictable, aversive events (Grillon, 2009; Rosen and Schulkin, 1998). Although names for this anxious phenotype vary from context fear to contextualization (Grillon, 2002; Liberzon and Sripada, 2008) and may have similarities to sustained fear (Davis et al, 2010; Miles et al, 2011) or the persistent 
increase in 'baseline' startle in both noise and light + noise trials coinciding with the first light fear CS presentation (Walker and Davis, 2002b), we think background anxiety - a state not directly related to cue-specific fear, but activated by the cue and sustained beyond the immediate threat-captures the essence of this behavioral phenotype. It has further been conceptualized that fear to specific, predictable threats ride upon this elevated background anxiety in PTSD and panic disorder (Grillon, 2002). Elucidating the mechanisms that oxytocin reduces background anxiety might be important for development of novel therapeutics.

\section{ACKNOWLEDGEMENTS}

This work was supported by Grant W81XWH-08-1-0182 from the Congressionally Directed Medical Research Programs, U.S. Army Medical Research \& Materiel Command.

\section{DISCLOSURE}

The authors declare no conflict of interest.

\section{REFERENCES}

Amico JA, Vollmer RR, Karam JR, Lee PR, Li X, Koenig JI et al (2004). Centrally administered oxytocin elicits exaggerated grooming in oxytocin null mice. Pharmacol, Biochem, Behav 78: 333-339.

Bale TL, Davis AM, Auger AP, Dorsa DM, McCarthy MM (2001). CNS region-specific oxytocin receptor expression: importance in regulation of anxiety and sex behavior. J Neurosci 21: 2546-2552.

Bartz J, Hollander E (2008). Oxytocin and experimental therapeutics in autism spectrum disorders. Prog Brain Res 170: 451-462.

Bartz JA, Zaki J, Bolger N, Hollander E, Ludwig NN, Kolevzon A et al (2010). Oxytocin selectively improves empathic accuracy. Psychol Sci 21: 1426-1428.

Bernier R, Dawson G, Panagiotides H, Webb S (2005). Individuals with autism spectrum disorder show normal responses to a fear potential startle paradigm. J Autism Dev Disord 35: 575-583.

Blume A, Bosch OJ, Miklos S, Torner L, Wales L, Waldherr M et al (2008). Oxytocin reduces anxiety via ERK1/2 activation: local effect within the rat hypothalamic paraventricular nucleus. Eur $J$ Neurosci 27: 1947-1956.

Boccia MM, Kopf SR, Baratti CM (1998). Effects of a single administration of oxytocin or vasopressin and their interactions with two selective receptor antagonists on memory storage in mice. Neurobiol Learn Mem 69: 136-146.

Born J, Lange T, Kern W, McGregor GP, Bickel U, Fehm HL (2002). Sniffing neuropeptides: a transnasal approach to the human brain. Nat Neurosci 5: 514-516.

Brasnjevic I, Steinbusch HWM, Schmitz C, Martinez-Martinez P (2009). Delivery of peptide and protein drugs over the bloodbrain barrier. Prog Neurobiol 87: 212-251.

Brunetti M, Sepede G, Mingoia G, Catani C, Ferretti A, Merla A et al (2010). Elevated response of human amygdala to neutral stimuli in mild post traumatic stress disorder: neural correlates of generalized emotional response. Neuroscience 168: 670-679.

Buijs R, de Vries G, van Leeuwen FW (1985). The distribution and synaptic release of oxytocin in the central nervous system, In: Amico J, Robinson A (eds). Oxytocin: Clincial and Laboratory Studies. Elsevier: Amsterdam. pp 77-86.
Buijs RM (1980). Immunocytochemical demonstration of vasopressin and oxytocin in the rat brain by light and electron microscopy. J Histochem Cytochem 28: 357-360.

Carson DS, Hunt GE, Guastella AJ, Barber L, Cornish JL, Arnold JC et al (2010). Systemically administered oxytocin decreases methamphetamine activation of the subthalamic nucleus and accumbens core and stimulates oxytocinergic neurons in the hypothalamus. Addict Biol 15: 448-463.

Carter C, Grippo A, Pournajafi-Nazarloo H, Ruscio M, Porges S (2008). Oxytocin, vasopressin and sociality. Prog Brain Res 170: 331-336.

Colbern DL, Gispen WH (1988). Neural mechanisms and biological significance of grooming behavior. Ann N Y Acad Sci 525: ix-x.

Davis M, Falls WA, Campeau S, Kim M (1993). Fear-potentiated startle: a neural and pharmacological analysis. Behav Brain Res 58: $175-198$.

Davis M, Walker DL, Miles L, Grillon C (2010). Phasic vs sustained fear in rats and humans: role of the extended amygdala in fear $v s$ anxiety. Neuropsychopharmacology 35: 105-135.

Davis M, Whalen PJ (2001). The amygdala: vigilance and emotion. Mol Psychiatry 6: 13-34.

de Oliveira LF, Camboim C, Diehl F, Consiglio AR, Quillfeldt JA (2007). Glucocorticoid-mediated effects of systemic oxytocin upon memory retrieval. Neurobiol Learn Mem 87: 67-71.

de Wied D, Gaffori O, Burbach JP, Kovács GL, van Ree JM (1987). Structure activity relationship studies with C-terminal fragments of vasopressin and oxytocin on avoidance behaviors of rats. J Pharmacol Exp Ther 241: 268-274.

Dichter GS, Benning SD, Holtzclaw TN, Bodfish JW (2010). Affective modulation of the startle eyeblink and postauricular reflexes in autism spectrum disorder. J Autism Dev Disord 40: 858-869.

Domes G, Heinrichs M, Gläscher J, Büchel C, Braus DF, Herpertz SC (2007). Oxytocin attenuates amygdala responses to emotional faces regardless of valence. Biol Psychiatry 62: 1187-1190.

Drago F, Pedersen CA, Caldwell JD, Prange AJ (1986). Oxytocin potently enhances novelty-induced grooming behavior in the rat. Brain Res 368: 287-295.

Durham DA, Banks WA, Kastin AJ (1991). Carrier-mediated transport of labeled oxytocin from brain to blood. Neuroendocrinology 53: 447-452.

Ermisch A, Barth T, Ruhle HJ, Skopkova J, Hrbas P, Landgraf R (1985). On the blood-brain barrier to peptides: accumulation of labeled vasopressin, DesGlyNH2-vasopressin and oxytocin by brain regions. Endocrinol Exp 19: 29-37.

Ermisch A, Brust P, Kretzschmar R, Rühle HJ (1993). Peptides and blood-brain barrier transport. Physiol Rev 73: 489-527.

Francis AB, Pace TW, Ginsberg AB, Rubin BA, Spencer RL (2006). Limited brain diffusion of the glucocorticoid receptor agonist RU28362 following i.c.v. administration: implications for i.c.v. drug delivery and glucocorticoid negative feedback in the hypothalamic-pituitary-adrenal axis. Neuroscience 141: 1503-1515.

Gibbs J, Kulkosky PJ, Smith GP (1981). Effects of peripheral and central bombesin on feeding behavior of rats. Peptides 2(Suppl 2): 179-183.

Gimpl G, Fahrenholz F (2001). The oxytocin receptor system: structure, function, and regulation. Physiol Rev 81: 629-683.

Grillon C (2002). Startle reactivity and anxiety disorders: aversive conditioning, context, and neurobiology. Biol Psychiatry 52: 958-975.

Grillon C (2009). D-cycloserine facilitation of fear extinction and exposure-based therapy might rely on lower-level, automatic mechanisms. Biol Psychiatry 66: 636-641.

Grillon C, Baas J (2003). A review of the modulation of the startle reflex by affective states and its application in psychiatry. Clin Neurophysiol 114: 1557-1579. 
Grillon C, Lissek S, Rabin S, Mcdowell D, Dvir S, Pine DS (2008). Increased anxiety during anticipation of unpredictable but not predictable aversive stimuli as a psychophysiologic marker of panic disorder. Am J Psychiatry 165: 898-904.

Grillon C, Morgan CA (1999). Fear-potentiated startle conditioning to explicit and contextual cues in Gulf War veterans with posttraumatic stress disorder. J Abnorm Psychol 108: 134-142.

Grillon C, Morgan III CA, Davis M, Southwick SM (1998). Effects of experimental context and explicit threat cues on acoustic startle in Vietnam veterans with posttraumatic stress disorder. Biol Psychiatry 44: 1027-1036.

Grillon C, Morgan CA, Southwick SM, Davis M, Charney DS (1996). Baseline startle amplitude and prepulse inhibition in Vietnam veterans with posttraumatic stress disorder. Psychiatry Res 64: 169-178.

Grillon C, Pine DS, Lissek S, Rabin S, Bonne O, Vythilingam M (2009). Increased anxiety during anticipation of unpredictable aversive stimuli in posttraumatic stress disorder but not in generalized anxiety disorder. Biol Psychiatry 66: 47-53.

Grippo AJ, Trahanas DM, Zimmerman II RR, Porges SW, Carter CS (2009). Oxytocin protects against negative behavioral and autonomic consequences of long-term social isolation. Psychoneuroendocrinology 34: 1542-1553.

Hogle JM, Kaye JT, Curtin JJ (2010). Nicotine withdrawal increases threat-induced anxiety but not fear: neuroadaptation in human addiction. Biol Psychiatry 68: 719-725.

Hollander E, Bartz J, Chaplin W, Phillips A, Sumner J, Soorya L et al (2007). Oxytocin increases retention of social cognition in autism. Biol Psychiatry 61: 498-503.

Hollander E, Novotny S, Hanratty M, Yaffe R, DeCaria CM, Aronowitz BR et al (2003). Oxytocin infusion reduces repetitive behaviors in adults with autistic and Asperger's disorders. Neuropsychopharmacology 28: 193-198.

Johnson AK, Epstein AN (1975). The cerebral ventricles as the avenue for the dipsogenic action of intracranial angiotensin. Brain Res 86: 399-418.

Kirsch P, Esslinger C, Chen Q, Mier D, Lis S, Siddhanti S et al (2005). Oxytocin modulates neural circuitry for social cognition and fear in humans. J Neurosci 25: 11489-11493.

Kiss A, Mikkelsen JD (2005). Oxytocin - anatomy and functional assignments: a minireview. Endocr Regul 39: 97-105.

Klenerova V, Krejci I, Sida P, Hlinak Z, Hynie S (2009). Modulary effects of oxytocin and carbetocin on stress-induced changes in rat behavior in the open-field. J Physiol Pharmacol 60: 57-62.

Kosfeld M, Heinrichs M, Zak PJ, Fischbacher U, Fehr E (2005). Oxytocin increases trust in humans. Nature 435: 673-676.

Liberzon I, Sripada CS (2008). The functional neuroanatomy of PTSD: a critical review. Prog Brain Res 167: 151-169.

Mens WB, Witter A, van Wimersma Greidanus TB (1983). Penetration of neurohypophyseal hormones from plasma into cerebrospinal fluid (CSF): half-times of disappearance of these neuropeptides from CSF. Brain Res 262: 143-149.

Miles L, Davis M, Walker D (2011). Phasic and sustained fear are pharmacologically dissociable in rats. Neuropsychopharmacology 36: 1563-1574.

Missig G, Ayers LW, Schulkin J, Rosen JB (2010). Oxytocin reduces background anxiety in a fear-potentiated startle paradigm. Neuropsychopharmacology 35: 2607-2616.

Morgan CA, Grillon C, Southwick SM, Davis M, Charney DS (1995). Fear-potentiated startle in posttraumatic stress disorder. Biol Psychiatry 38: 378-385.

Neumann ID (2008). Brain oxytocin: a key regulator of emotional and social behaviors in both females and males. J Neuroendocrinol 20: 858-865.

Pardridge WM (2005). The blood-brain barrier: bottleneck in brain drug development. NeuroRx 2: 3-14.
Petersson M, Alster P, Lundeberg T, Uvnas-Moberg K (1996). Oxytocin causes a long-term decrease of blood pressure in female and male rats. Physiol Behav 60: 1311-1315.

Petersson M, Hulting AL, Uvnas-Moberg K (1999). Oxytocin causes a sustained decrease in plasma levels of corticosterone in rats. Neurosci Lett 264: 41-44.

Pole N, Neylan TC, Best SR, Orr SP, Marmar CR (2003). Fearpotentiated startle and posttraumatic stress symptoms in urban police officers. J Traum Stress 16: 471-479.

Pole N, Neylan TC, Otte C, Henn-Hasse C, Metzler TJ, Marmar CR (2009). Prospective prediction of posttraumatic stress disorder symptoms using fear potentiated auditory startle responses. Biol Psychiatry 65: 235-240.

Reeb-Sutherland BC, Helfinstein SM, Degnan KA, Pérez-Edgar K, Henderson HA, Lissek $S$ et al (2009). Startle response in behaviorally inhibited adolescents with a lifetime occurrence of anxiety disorders. J Am Acad Child Adolesc Psychiatry 48: 610-617.

Ring RH, Malberg JE, Potestio L, Ping J, Boikess S, Luo B et al (2006). Anxiolytic-like activity of oxytocin in male mice: behavioral and autonomic evidence, therapeutic implications. Psychopharmacology (Berl) 185: 218-225.

Rosen JB, Schulkin J (1998). From normal fear to pathological anxiety. Psychol Rev 105: 325-350.

Rotzinger S, Lovejoy DA, Tan LA (2010). Behavioral effects of neuropeptides in rodent models of depression and anxiety. Peptides 31: 736-756.

Sawchenko P, Swanson L (1985). Relationship of oxytocin pathways to the control of neuroendocrine and autonomic function, In: Amico J, Robinson A (eds). Oxytocin: Clinical and Laboratory Studies. Elsevier: Amsterdam. pp 87-103.

Simeon D, Bartz J, Hamilton H, Crystal S, Braun A, Ketay S et al (2011). Oxytocin administration attenuates stress reactivity in borderline personality disorder: a pilot study. Psychoneuroendocrinology; doi:10.1016/j.psyneuen.2011.03.013.

Simpson JB (1975). Subfornical organ involvement in angiotensininduced drinking, In: Fitzsimons JT, Peters-Haefeli L (eds). Control Mechanisms of Drinking. Springer-Verlag: New York.

Slattery DA, Neumann ID (2010). Chronic icv oxytocin attenuates the pathological high anxiety state of selectively bred Wistar rats. Neuropharmacology 58: 56-61.

Sofroniew MV (1983). Morphology of vasopressin and oxytocin neurones and their central and vascular projections. Prog Brain Res 60: 101-114.

Stivers JA, Kaltwasser MT, Hill PS, Hruby VJ, Crawley JN (1988). Ventral tegmental oxytocin induces grooming. Peptides 9 (Suppl 1): 223-231.

Tribollet E, Dubois-Dauphin M, Dreifuss JJ, Barberis C, Jard S (1992). Oxytocin receptors in the central nervous system. Distribution, development, and species differences. Ann NY Acad Sci 652: 29-38.

Uvnäs-Moberg K, Ahlenius S, Hillegaart V, Alster P (1994). High doses of oxytocin cause sedation and low doses cause an anxiolytic-like effect in male rats. Pharmacol Biochem Behav 49: 101-106.

Van Erp AM, Kruk MR, De Kloet ER (1993a). Induction of grooming in resting rats by intracerebroventricular oxytocin but not by adrenocorticotropic hormone-(1-24) and alpha-melanocyte-stimulating hormone. Eur J Pharmacol 232: 217-221.

Van Erp AM, Kruk MR, Semple DM, Verbeet DW (1993b). Initiation of self-grooming in resting rats by local PVH infusion of oxytocin but not alpha-MSH. Brain Res 607: 108-112.

Veening JG, de Jong T, Barendregt HP (2010). Oxytocin-messages via the cerebrospinal fluid: behavioral effects; a review. Physiol Behav 101: 193-210.

Viviani D, Stoop R (2008). Opposite effects of oxytocin and vasopressin on the emotional expression of the fear response. Prog Brain Res 170: 207-218. 
Walker DL, Davis M (2002a). Quantifying fear potentiated startle using absolute $v s$ proportional increase scoring methods: implications for the neurocircuitry of fear and anxiety. Psychopharmacology (Berl) 164: 318-328.

Walker DL, Davis M (2002b). The role of amygdala glutamate receptors in fear learning, fear-potentiated startle, and extinction. Pharmacol Biochem Behav 71: 379-392.
Wilbarger JL, McIntosh DN, Winkielman P (2009). Startle modulation in autism: positive affective stimuli enhance startle response. Neuropsychologia 47: 1323-1331.

Windle RJ, Shanks N, Lightman SL, Ingram CD (1997). Central oxytocin administration reduces stress-induced corticosterone release and anxiety behavior in rats. Endocrinology 138: 2829-2834.

Supplementary Information accompanies the paper on the Neuropsychopharmacology website (http://www.nature.com/npp) 